\title{
Lipofuscinosis of the gastrointestinal tract in man
}

\author{
BERNARD FOX \\ From the Department of Morbid Anatomy, Charing Cross Hospital Medical School, London
}

SYNOPSIS Three illustrative cases of lipofuscinosis of the gastrointestinal tract are presented.

The nature and significance of this condition are discussed. When the pigment is found in surgical biopsy material steatorrhoea, hypoalbuminaemia, and vitamin E deficiency should be excluded. It is probable that this type of lipofuscinosis is a manifestation of vitamin $\mathrm{E}$ deficiency in man.

Brown pigmentation (lipofuscinosis) of the bowel was first recorded in necropsy material from patients dying from a variety of diseases (Blaschko, 1883; Scheimpflug, 1885). The pigmentation was described as being mainly in the small intestine and was thought to be a degenerative change. Pappenheimer and Victor (1946) reported pigmentation in the smooth muscle of the oesophagus, stomach, and small intestine in necropsy material from patients with the malabsorption syndrome. This observation has been confirmed in idiopathic steatorrhoea (Adlersberg and Schein, 1947; Ansanelli and Lane, 1957; Gresham, Cruickshank, and Valentine, 1958; Parkhurst, Grube, and Neumann, 1964) and in steatorrhoea due to chronic pancreatitis (Braunstein, 1961; Fullerton, 1960; Toffler, Hukill, and Spiro, 1963), fibrocystic disease of the pancreas (Kerner and Goldbloom, 1960; Blanc, Reid, and Andersen, 1958), Whipple's disease (Gresham et al., 1958; Kent, Layton, Clifton, and Schedl, 1963), and, duodenal and jejunal diverticulosis (Fullerton 1960; Richards, 1959; Binder, Herting, Hurst, Finch, and Spiro, 1965). It has been regarded as the anatomical hallmark of malabsorption of fat and vitamin $E$ (Pappenheimer and Victor, 1946), and as of diagnostic value in idiopathic steatorrhoea and Whipple's disease (Gresham et al., 1958).

Jarnum (1963) found that in various cases of protein-losing gastroenteropathy, hypoproteinaemia was often associated with pigmentation of the small intestine. Waldmann, Steinfeld, Dutcher, Davidson, and Gordon (1961) in their cases of idiopathic hypoproteinaemia with intestinal lymphangiectasia often found pigmentation of the small intestine.

Pappenheimer and Victor (1946) and Fullerton (1960) also found intestinal pigmentation in cases of Laënnec's cirrhosis, but they did not mention whether there was hypoproteinaemia.

Received for publication 27 April 1967.
This paper describes three cases of lipofuscin pigmentation of the gastrointestinal tract discovered in surgical biopsy material, describes in detail the histological distribution and staining characteristics of the pigment, discusses the significance of the finding, and emphasises its diagnostic value in the malabsorption syndrome, hypoproteinaemia, and vitamin E deficiency.

\section{CASE REPORTS}

CASE 1 A 61-year-old man was admitted to hospital in 1963 for investigation of indigestion and recent loss of $13 \mathrm{~kg}$. There was pitting oedema of the ankles which had been present intermittently for 35 years, and tenderness in the left hypochondrium. Investigations showed $\mathrm{Hb} 10 \cdot 1 \mathrm{~g} . / 100 \mathrm{ml}$., total serum proteins $4.2 \mathrm{~g} . / 100 \mathrm{ml}$. (albumin $2.2 \mathrm{~g} . / 100 \mathrm{ml}$., globulin $2.0 \mathrm{~g} . / 100 \mathrm{ml}$.). No albumin was detected in the urine. A barium meal showed coarse mucosal folds and a 'cup and spill' deformity. Although a repeat examination was advised the patient left hospital but shortly afterwards he was admitted to another hospital with haematemesis and melaena. He then returned to Charing Cross Hospital where a barium meal examination now showed a carcinoma of the stomach. He had a total gastrectomy (Mr. P. F. Philip) and as the jejunum was thickened, brown and had prominent lacteals a biopsy was taken. He died eight days after the operation.

Surgical specimens The whole of the stomach wall was involved by a highly cellular anaplastic carcinoma. Microscopy of the jejunum showed dilated lymphatics, many of which contained foamy lipophages, in the villi and submucosa (Figs. 1 and 2). There was marked submucosal oedema and very marked lipofuscinosis.

Necropsy There was light brown pigmentation of the whole of the first $30 \mathrm{~cm}$. of the jejunum, more marked on the mesenteric border. There were dilated, yellowish lacteals in the serosa of the whole of this part of the jejunum. Throughout the rest of the jejunum and the whole of the ileum there were areas of brown pigmentation about 3 to $5 \mathrm{~cm}$. long interspersed between 10 to $30 \mathrm{~cm}$. lengths of normal looking bowel. In the left lobe 


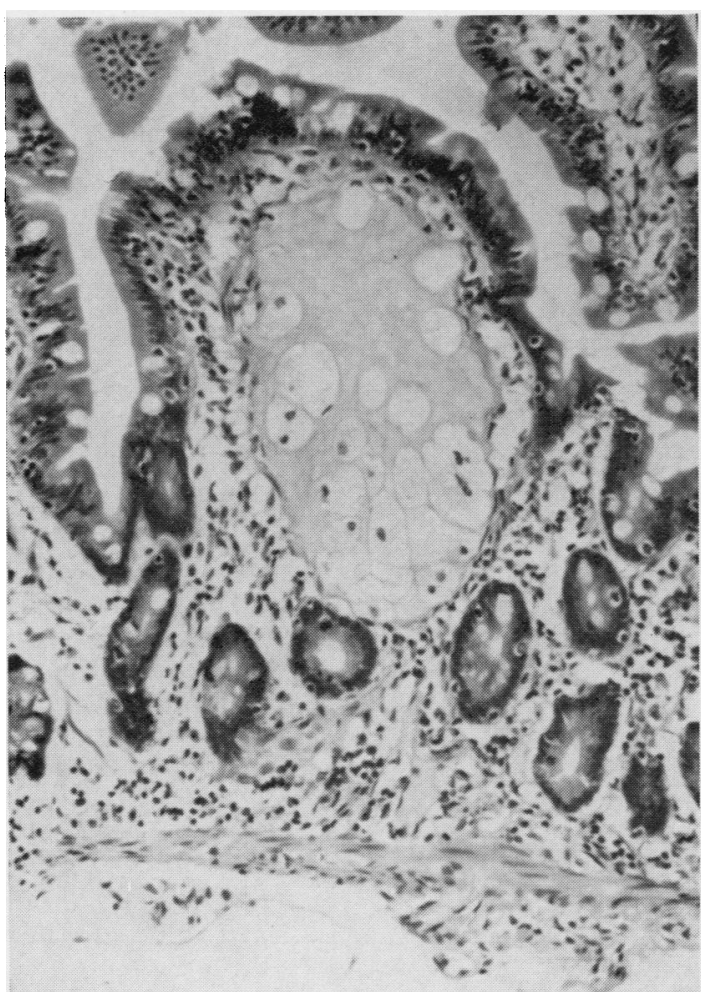

FIG. 1. Case 1 Jejunum: villus with dilated lymphatics containing lipophages. Haemalum and eosin $\times 65$.

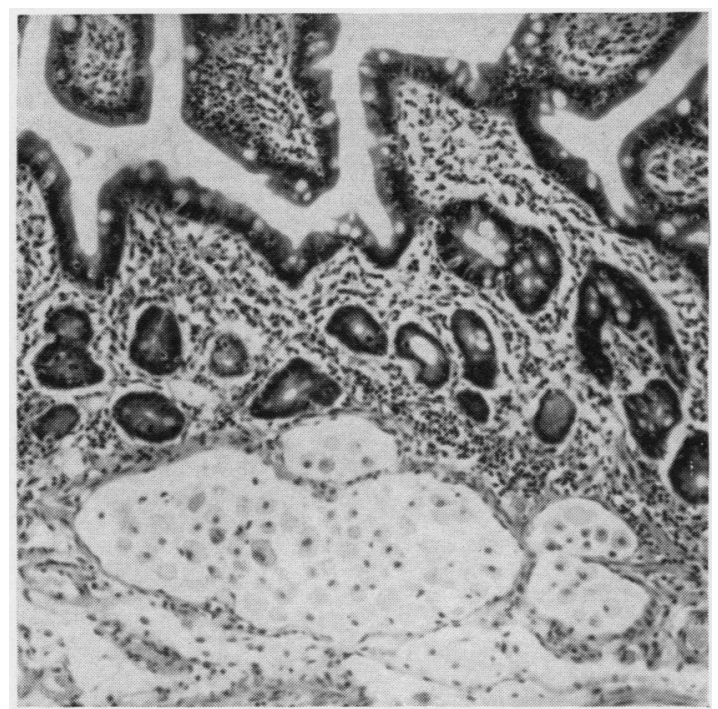

FIG. 2. Case I Jejunum: dilated submucosal lymphatics containing lipophages. Haemalum and eosin $\times 65$. of the liver there were two circumscribed haemorrhagic areas which appeared to be true infarcts. The trachea and bronchi were inflamed and there was congestion and oedema of the whole of both lungs. Both kidneys were greyish-white and oedematous and microscopy showed marked tubular necrosis with some evidence of healing.

Microscopical examination Pigment was found in cells of small intestine, mesenteric lymph nodes, brain, testes, and liver. Details of its distribution are given in Table II.

The small intestine showed lymphangiectasia similar to that in the surgical specimen of the jejunum. There was no pigment in bone, pituitary, bladder, skin, prostate, thyroid or skeletal muscle.

The final diagnoses were renal tubular necrosis, pulmonary oedema, suppurative bronchitis, myocardial degeneration, hypoproteinaemia due to intestinal lymphangiectasia (Waldmann et al., 1961), total gastrectomy for anaplastic carcinoma of the stomach, ischaemic segmental necrosis of the left adrenal, and lipofuscinosis. The 35-year history of oedema was probably due to hypoproteinaemia which was caused by intestinal lymphangiectasia.

CASE 2 A 72-year-old woman was seen in the Outpatient Department in May 1960 with a 40-year history of indigestion. There were no abnormal physical signs, but a fractional test meal showed very high gastric acidity. A barium meal showed evidence of a pyloric ulcer. In 1961 she was admitted to hospital with a history of vomiting and a loss of $8 \mathrm{~kg}$. over six weeks. A barium meal showed pyloric stenosis with some irregularity of the lesser curve.

At laparotomy (Mr. H. Cochrane) there was a chronic duodenal ulcer with pyloric stenosis, and a chronic gastric ulcer on the lesser curve. The small intestine was strikingly pigmented and at the time was described as heavily stained with bile.

The patient made a complete recovery from the operation and in January 1964 total serum proteins were $6.6 \mathrm{~g} . / 100 \mathrm{ml}$.

Surgical specimens There was an active chronic gastric ulcer and two small acute gastric ulcers on the lesser curve. There was chronic cholecystitis but no lipofuscin pigment in the gall bladder.

The biopsy of jejunum showed normal villi and gross lipofuscin pigmentation of the muscle layers (Table II).

CASE 3 A 65-year-old woman was admitted to hospital after having passed heavily bloodstained faeces. The only abnormal clinical signs were obvious anaemia and some tenderness in the right hypochondrium. Three days after admission she had a severe haematemesis. At laparotomy (Mr B. P. Bliss) there was a large chronic duodenal ulcer which involved the gall bladder and penetrated the pancreas. A standard Polya gastrectomy was carried out, and the distal part of the ulcer was also removed. Serum albumin $3.0 \mathrm{~g} . / 100 \mathrm{ml}$, globulin $3.0 \mathrm{~g}$./ $100 \mathrm{ml}$. She was discharged from hospital 12 days after the operation. She did not come for further consultation but it was thought that hypoproteinaemia was due to chronic alcoholism. 
Surgical specimens Partial gastrectomy specimen with edge of an active chronic duodenal ulcer and chronic inflammation of the stomach wall. Lipofuscin pigment was seen in the stomach and duodenum (Table II).

\section{STAINING PROPERTIES OF THE PIGMENT (TABLE I)}

With haemalum and eosin the pigment was brown and in unstained sections yellowish brown. There was variation in the intensity of the colour within muscle fibres, and in macrophages the pigment stained more intensely.

The results of the staining reactions are set out in Table I, and identify the pigment as a lipofuscin.

In all preparations stained by any of the methods there were always collections of unstained pigment; a rough estimate showed that about $20 \%$ of the pigment did not stain with periodic acid Schiff (P.A.S.) and Long $\mathrm{ZN}$, and $10 \%$ did not stain with Sudan black B, Nile Blue, chrome haematoxylin and Schmorl ferric ferricyanide reaction. Only a small amount of pigment, less than $10 \%$, reduced ammoniacal silver nitrate. Most of the pigment gave a yellowish green autofluorescence in ultraviolet light.

These findings suggest that the pigment is a mixture of lipofuscin at different stages of formation.
The staining reactions of the pigment in the heart (case 1) were different from those of the pigment in other tissues and were characteristic of the lipochrome so often found in the heart.

The staining reactions of the pigment in the testes, brain, and liver in case 1 were very similar to those of the pigment in the small intestine, except that it did not stain with chrome alum haematoxylin.

\section{DISTRIBUTION AND MICROSCOPICAL APPEARANCES OF THE PIGMENT}

Distribution of the pigment is summarized in Table II.

Pigmentation was usually most marked in the muscular coats although there was considerable variation in its $N$ distribution in different sections examined.

The lipofuscin mainly appeared as granules of irregular shape which varied from less than $1 \mu$ to up to $6 \mu$ in diameter; it was occasionally rod shaped. The muscle 윽 fibres were often diffusely involved (Fig. 3) but occasionally pigment was confined to the juxtanuclear region. Pigment was also found inside vacuoles within muscle fibres, and occasionally appeared only at the periphery of the vacuoles. In sections from the more severely affected areas of jejunum stained with phosphotungstic

TABLE I

STAINING PROPERTIES OF THE PIGMENT IN PARAFFIN SECTIONS

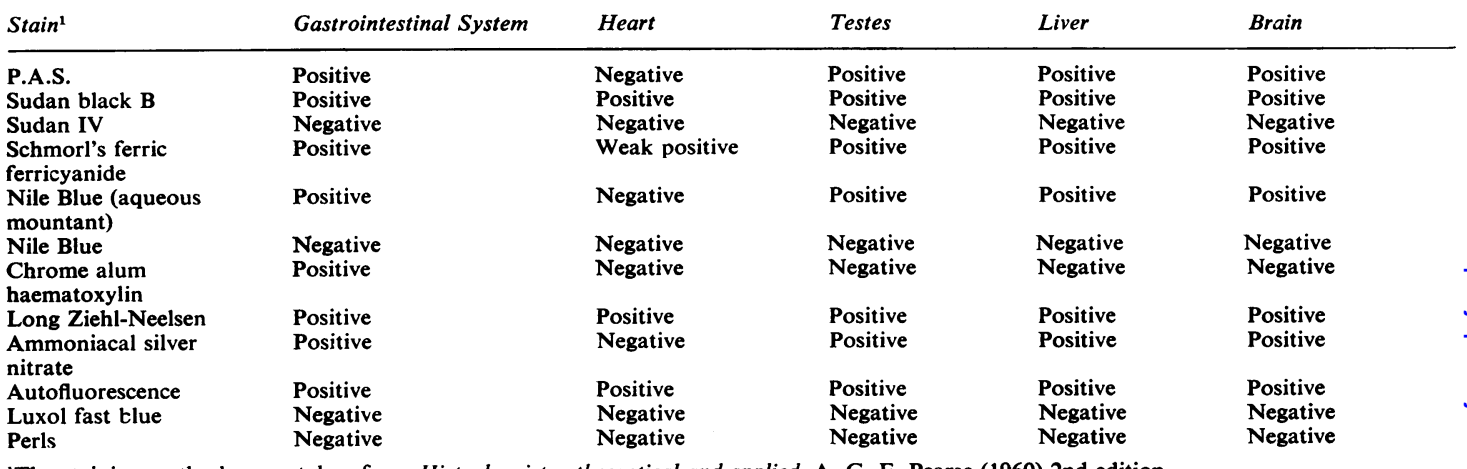

'The staining methods were taken from Histochemistry theoretical and applied, A. G. E. Pearse (1960) 2nd edition.

TABLE II

DISTRIBUTION OF PIGMENT

\begin{tabular}{|c|c|c|c|c|c|c|c|c|c|c|c|c|}
\hline \multirow{3}{*}{$\begin{array}{l}\text { Case } \\
\text { No. }\end{array}$} & \multicolumn{5}{|l|}{ Smooth Muscle } & \multirow{3}{*}{$\begin{array}{l}\text { Blood Vessels } \\
\text { in Stomach } \\
\text { and Small } \\
\text { Intestine }\end{array}$} & \multicolumn{2}{|c|}{ Macrophages } & \multirow[t]{3}{*}{ Brain $^{1}$} & \multirow[t]{3}{*}{ Liver $^{2}$} & \multirow[t]{3}{*}{ Heart $^{3}$} & \multirow[t]{3}{*}{ Testes } \\
\hline & \multirow{2}{*}{$\begin{array}{l}\text { Oesophagus } \\
\begin{array}{l}\text { Muscularis Muscular } \\
\text { Mucosa Coat }\end{array}\end{array}$} & \multicolumn{2}{|l|}{ Stomach } & \multicolumn{2}{|c|}{ Small Intestine } & & & & & & & \\
\hline & & $\begin{array}{l}\text { Muscularis } \\
\text { Mucosa }\end{array}$ & $\begin{array}{l}\text { s Muscular } \\
\text { Coat }\end{array}$ & $\begin{array}{l}\text { Muscularis } \\
\text { Mucosa }\end{array}$ & $\begin{array}{l}\text { Muscular } \\
\text { Coat }\end{array}$ & & $\begin{array}{l}\text { and Intes- } \\
\text { tine Wall }\end{array}$ & Nodes & & & & \\
\hline $\begin{array}{l}1 \\
2 \\
3\end{array}$ & $\begin{array}{l}-{ }^{+}+ \\
\text {Not examined } \\
\text { Not examined }\end{array}$ & $\begin{array}{l}- \\
+ \\
+\end{array}$ & $\begin{array}{l}+ \\
+\end{array}$ & $\begin{array}{l}- \\
+\end{array}$ & $\begin{array}{l}+++ \\
+++ \\
+++\end{array}$ & $\begin{array}{l}++ \\
+ \\
++\end{array}$ & $\begin{array}{l}+++ \\
++ \\
++\end{array}$ & $\begin{array}{l}+ \\
\stackrel{+}{\text { Not }} \\
\text { examined }\end{array}$ & + & + & + & + \\
\hline
\end{tabular}




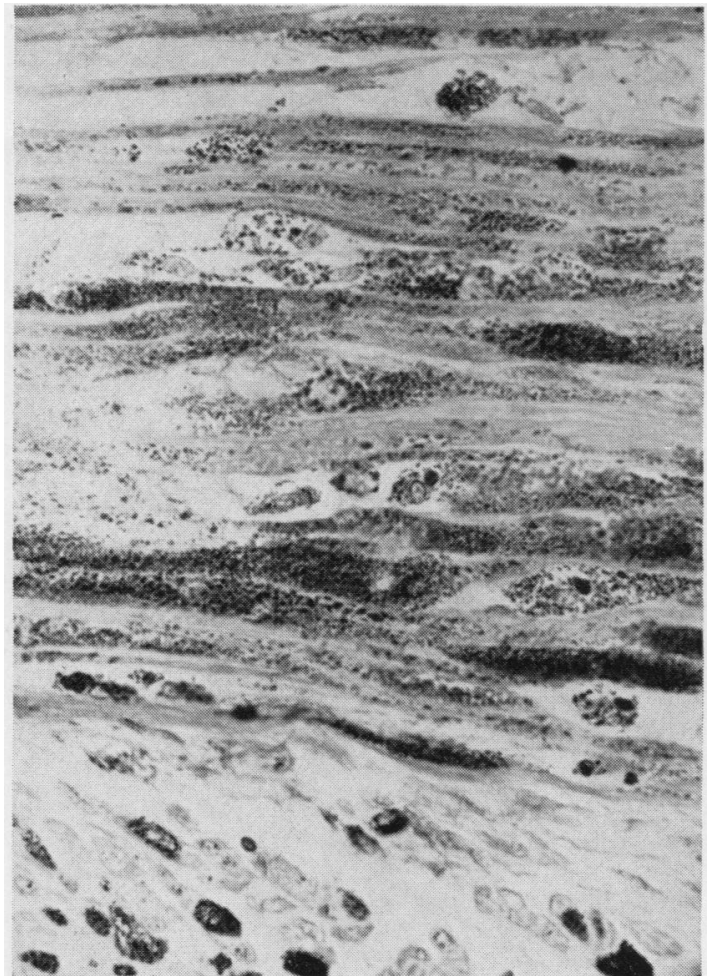

FIG. 3. Case 1 Jejunum: lipofuscin diffusely involving muscle fibres. Schmorl's ferric ferricyanide $\times 250$.

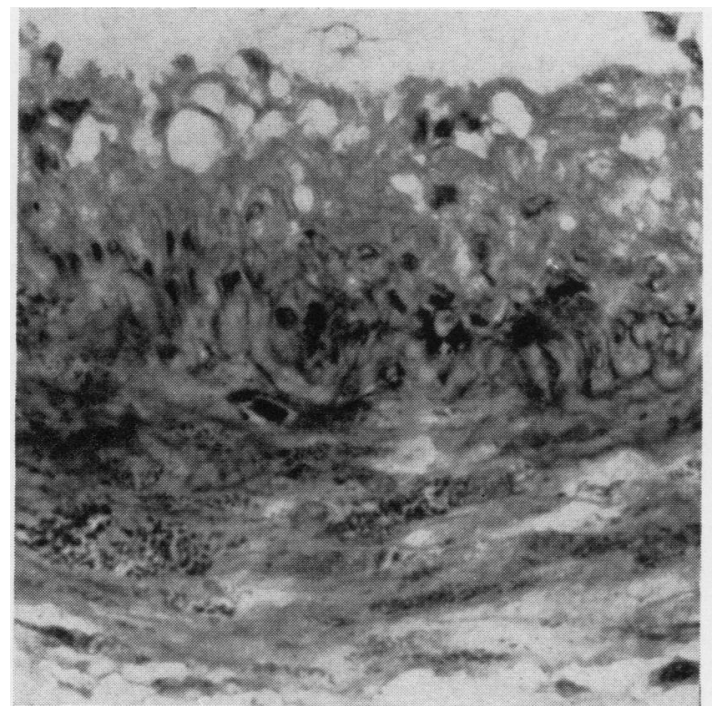

FIG. 5. Case 3 Lipofuscin in muscle fibres in wall of artery. Periodic-acid Schiff $\times 400$.

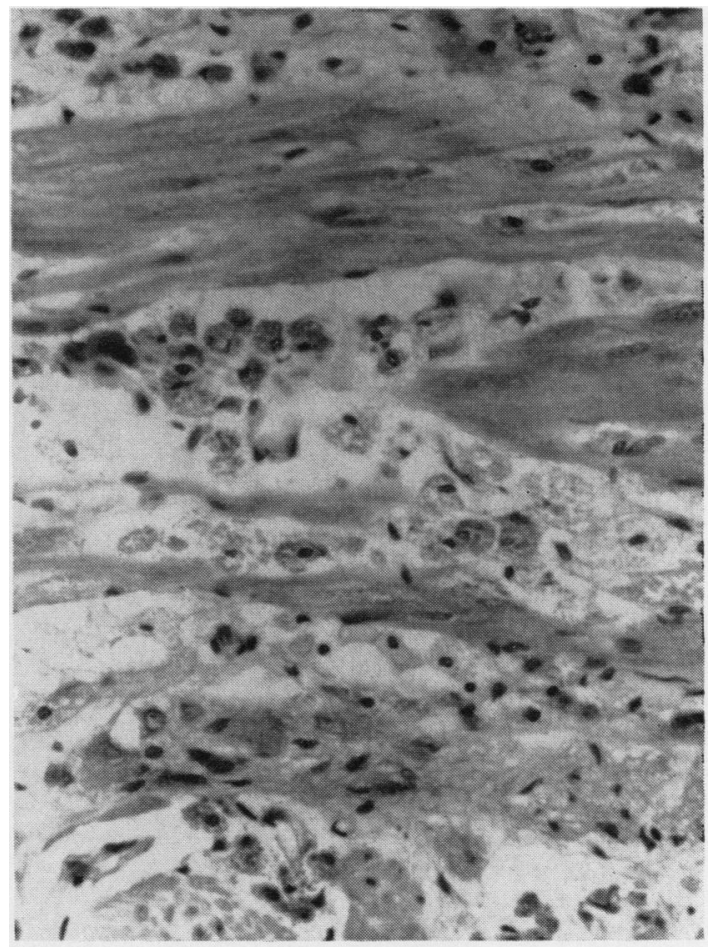

FIG. 4. Case 1 Jejunum: lipofuscin-filled macrophages in muscular wall. Haemalum and eosin $\times 190$.

acid haematoxylin there was an apparent loss of myofibrils (Fig. 6). The walls of arteries in the stomach, small intestine, and lymph nodes were often severely involved (Fig. 5).

In the more severely involved areas of stomach and intestine there were large numbers of lipofuscin-filled macrophages up to $25 \mu$ in diameter in the submucosa, in and around muscle fibres in the muscular coats, and in the subserosa (Fig. 4). There was an intricate relationship between the muscle fibres and the macrophages (Fig. 4). There was no pigment in the lamina propria of the mucosa or in the ganglion cells in the gastrointestinal tract.

\section{DISCUSSION}

The pigment in the three cases had the same staining properties although there was variation in the intensity of the reactions within the different tissues. Similar pigment found in the small intestine has been called ceroid, mainly because of its acid-fast properties and its similarity to the pigment described by Lillie, Daft, and Sebrell (1941) in the cirrhotic livers of animals maintained on a diet low in protein 


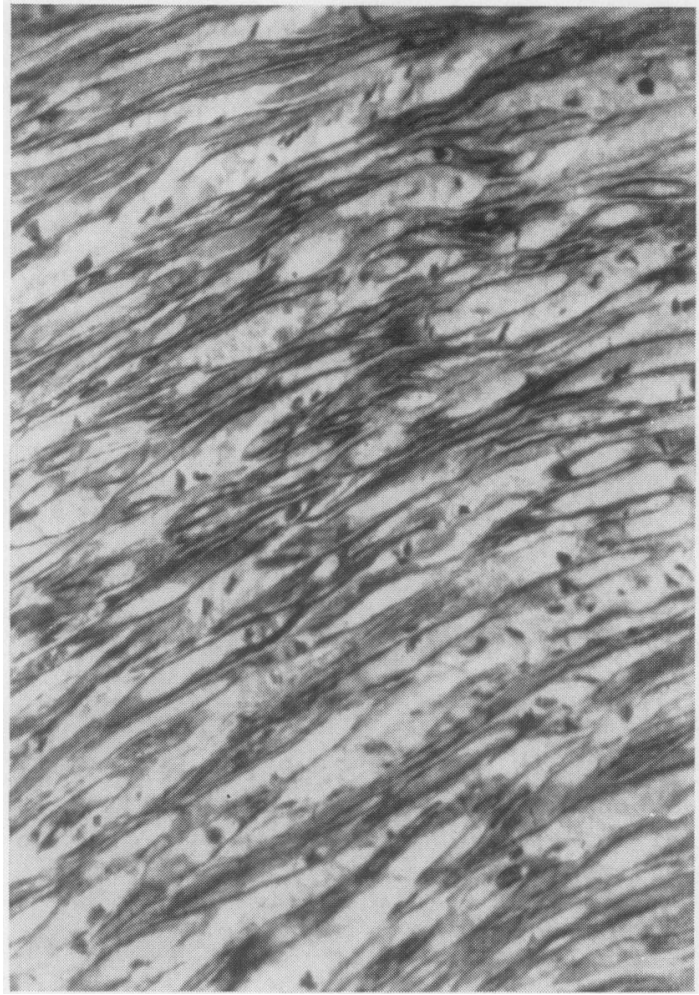

FIG. 6.

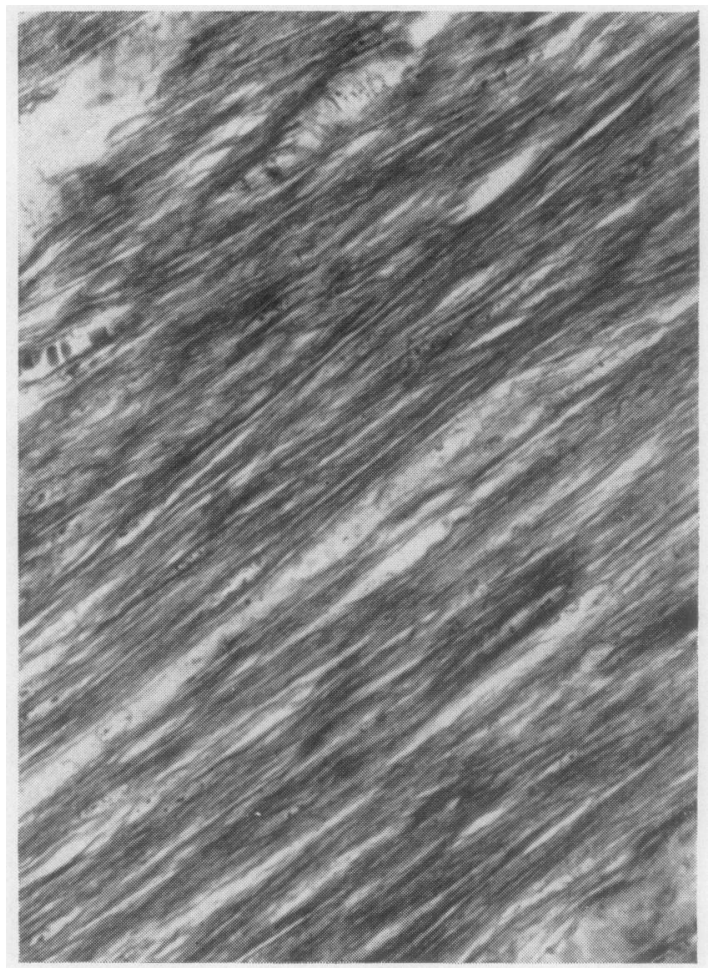

FIG. 7.

FIG. 6. Case 2 Jejunum: vacuolation and apparent loss of myofibrils in inner layer of muscular wall. Compare with normal jejunum in Figure 7. Phosphotungstic acid haematoxylin $\times 250 . \quad$ FIG. 7. Normal jejunum: innerlayer of muscular wall for comparison with Figure 6. Phosphotungstic acid haematoxylin $\times 250$.

and fat (Pappenheimer and Victor, 1946). Pearse (1960) regards ceroid as a mixture of substances and believes that it represents a typical lipofuscin in an early stage of oxidation.

In the specimens described above the staining reactions show that there was a mixture of pigments which are probably lipofuscins at different stages of oxidation. Although a high proportion of the pigments studied are acid-fast, they do not appear to be ceroid as they reduced ferric ferricyanide, a property which ceroid does not possess (Lillie, 1954; Pearse, 1960). About $70-80 \%$ of the pigment was stained by Sudan black B, a similar proportion reduced ferric ferricyanide, and only a small proportion reduced ammoniacal silver nitrate. These findings are difficult to equate with Pearse's view on the histogenesis of lipofuscins: in his diagram, which expresses the natural history of the lipofuscins in terms of the histochemical tests (Pearse, 1960, p. 662 , Fig. 207), the reaction with Sudan black B falls off as the Schmorl reaction increases, and as the Schmorl reaction increases, silver reduction also increases. Although the apparent discrepancy between his observation and the findings in the cases now described may be due to some mixture of lipofuscins, the fact that at least $70 \%$ of the pigment stained with Sudan black B and reduced ferric ferricyanide suggests that there is a considerably greater overlap in the histochemical reactions of developing lipofuscins than Pearse's diagram indicates.

The pigment in the small intestine in this type of case seems to have received little attention from histochemists. Neither Lillie (1954) nor Pearse (1960) in their textbooks mentions the presence of this pigment in the small intestine in man. In the more severe cases, as cases 1 and 2, the condition can be recognized during life, and such material could be a valuable source of fresh tissue for the histochemical investigation of lipofuscins in man.

Although there is agreement that the site of greatest pigmentation is the upper part of the small 


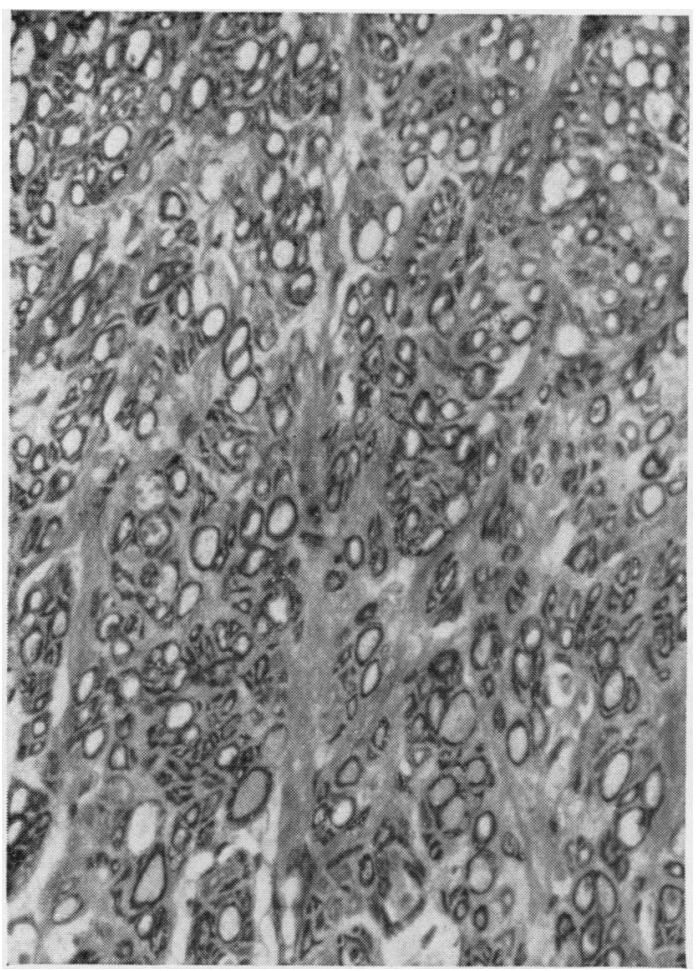

FIG. 8. Case 2 Jejunum: vacuolation of muscle fibres in outer layer of muscular wall. Phosphotungstic acid haematoxylin $\times 250$.

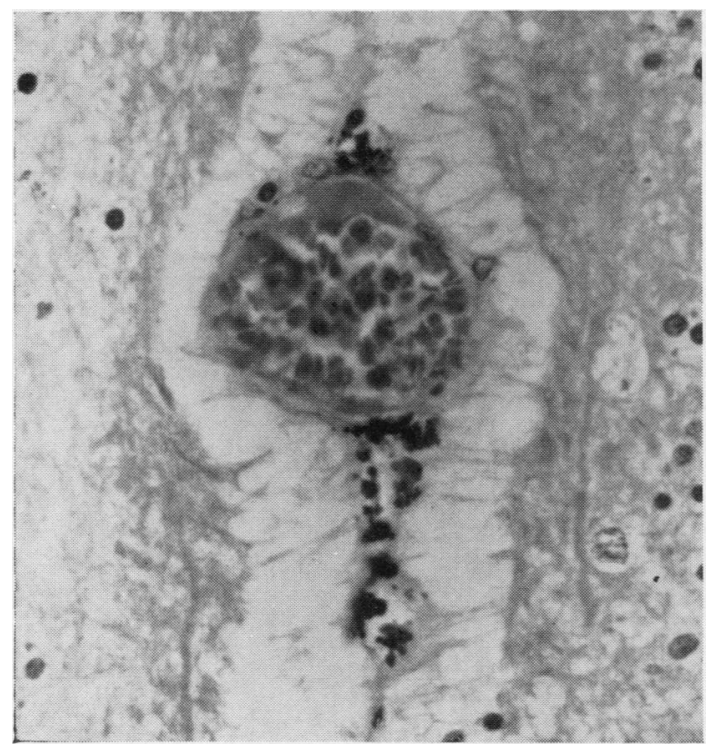

FIG. 9. Case 1 Lipofuscin in juxtavascular histiocytes in brain. Long Ziehl-Neelsen $\times 293$. intestine, there are significant variations in the described distribution of the pigment within the bowel wall.

In the present cases pigment was found in all the muscle layers of the intestine, including the muscularis mucosa; it was also found in the walls of blood vessels and within macrophages. Fullerton (1960), Pappenheimer and Victor (1946), Gresham et al. (1958), Kerner and Goldbloom (1960), and Toffler et al. (1963) did not find pigment in the muscularis mucosa; Adlersberg and Schein (1947) and Braunstein (1961) only found it within muscle fibres; Toffler et al. (1963) and Kerner and Goldbloom (1960) did not find it in blood vessels of the small intestine. These differences may be due to variation in the distribution of pigment in the different sections examined. Another reason for this variation is that there appears to be a direct relationship between the presence and extent of lipofuscin and the duration of the disease with which it is associated (Binder et al., 1965). It is interesting to note, however, that in case 1 , in which the pigmentation is very marked, there was no pigment in the muscularis mucosa.

The differential diagnosis from Whipple's disease could cause some difficulty if macrophages with P.A.S.-positive material were first seen in abdominal lymph nodes. However, the macrophages in Whipple's disease do not contain acid-fast material and do not stain with Sudan Black B in paraffin sections (Casselman, Macrea, and Simmons, 1954). Lipofuscinosis often occurs in Whipple's disease but there should be no difficulty in diagnosis if the small intestine is examined. In lipofuscinosis P.A.S.-positive material in macrophages is not seen in the lamina propria and is only found elsewhere when there is gross pigmentation of the muscle layers.

There are few reports of comparable lipofuscin pigmentation in man in tissues other than smooth muscle. Bogaert and Tverdy (1950), in a case of vitamin $\mathrm{E}$ deficiency due to sprue, found pigment within the cerebrum with a similar distribution to that found in case 1 . The quantity of lipofuscin in interstitial cells (Leydig cells) found in case 1 was greater than that found in the normal testis. The finding of pigment in the liver identical to that in the small intestine is uncommon. Pappenheimer and Victor (1946) found ceroid pigment in the liver in a case of steatorrhoea due to a gastro-colic fistula. Lipofuscins of this type cannot be broken down in vivo (Mason and Emmel, 1945) and it may be that in severe cases they are disseminated throughout the body through the lymphatics.

The cause of this pigmentation in man is not known but Pappenheimer and Victor (1946) were 
the first to suggest that it may be the direct result of vitamin $E$ deficiency occurring as an accompaniment of malabsorption of fat. Binder et al. (1965) found low serum levels of vitamin $E$ in patients with steatorrhoea and in some of these cases there was pigmentation of the muscle of the small intestine. Children with cystic fibrosis of the pancreas or biliary atresia have vitamin E deficiency (Nitowsky, Gordon, and Tildon, 1956) and study of necropsy material from such children shows that the great majority have pigmentation of the gastrointestinal tract (Blanc et al., 1958, Kerner and Goldbloom, 1960).

Monkeys, hamsters, dogs, and rats kept on a vitamin E-deficient diet develop brown pigmentation of smooth muscle fibres of various organs, including the small intestine (Mason and Emmel, 1945; Mason and Telford, 1947). Recently, Cordes and Mosher (1966) found marked lipofuscin pigmentation of the small intestine in dogs with low plasma tocopherol levels. Lindner (1954), using fluorescence microscopy, electron microscopy, and histochemistry, found that the pigment extracted from the uteri of vitamin E-deficient rats and that extracted from the small intestine in a case of sprue had similar properties.

There seems to be no doubt that vitamin $\mathrm{E}$ deficiency occurs in steatorrhoea and that it results in the deposition of lipofuscin pigment in the small intestine. As lipofuscins are formed mainly by the altered oxidation of unsaturated fatty acids, the lack of such a powerful antioxidant as vitamin $E$ would encourage lipofuscin formation. Tappel (1965) regards lipofuscin deposition in vitamin Edeficient animals to be directly related to lipid peroxidation which occurs in the absence of the antioxidant activity of the vitamin.

Lipofuscinosis also occurs in patients with hypoalbuminaemia (Richards, 1959; Schwartz and Jarnum, 1959; cases 1 and 3 of this paper), ulcerating lesions of the upper gastrointestinal tract (case 2 of this paper; Richards, 1959), and Laënnec's cirrhosis (Fullerton, 1960; Pappenheimer and Victor, 1946); therefore hypoalbuminaemia should be excluded in all cases in which pigmentation is found.

The reason for the association of lipofuscinosis with hypoalbuminaemia or with ulcerating lesions of the upper gastrointestinal tract is obscure, but recent work has suggested that vitamin $\mathrm{E}$ may be the common factor. There is a close interrelationship between vitamin $\mathrm{E}$ and protein metabolism. It appears that decreased absorption of protein or lowered serum proteins may contribute to vitamin E deficiency (Herting, 1966). Monkeys fed on a diet deficient in methionine develop vitamin $\mathrm{E}$ deficiency and they can be protected from this deficiency by supplementing the diet with methionine and cystine (Dinning, 1963).

Leonard, Losowsky, and Pulvertaft (1966) found low plasma vitamin $\mathrm{E}$ levels in peptic ulcer patients and they thought that the low levels could possibly be correlated with the length of history.

Although there seems to be no comment in the literature on functional disturbance resulting from lipofuscin pigmentation of the intestinal muscle, it must be possible that such pigment-filled and vacuolated muscle fibres as were found in these cases (Fig. 3, 6, and 8) would not function normally. It is unlikely that treatment with vitamin $\mathrm{E}$ would reverse the muscle changes in well-established cases, but it might prevent further spread of pigment (Mason and Emmel, 1945).

It seems probable that vitamin $\mathrm{E}$ deficiency in man is more common than has been suspected (Herting, 1966). In some cases of vitamin E deficiency there is decreased red cell survival time (Binder et al., 1965), and occasional resistant megaloblastic anaemias respond to vitamin E (Majaj, Dinning, Azzam, and Darby, 1963). Study of vitamin E in man should be stimulated by the awareness that lipofuscinosis of the gastrointestinal tract may be the result of vitamin E deficency.

I wish to thank Professor W. St. C. Symmers for his help in the preparation of this paper. My thanks are also due to Mr. F. D. Humberstone and Mr. K. James for technical assistance and to the photographic department of Charing Cross Hospital Medical School for the photomicrographs. I am indebted to Mr. N. C. Tanner, Mr. H. Cochrane, Mr. P. F. Phillip, and Dr. P. B. S. Fowler for permission to use the clinical notes of their cases.

\section{REFERENCES}

Aldersberg, D., and Schein, J. (1947). J. Amer. med. Ass., 134, 1459. Ansanelli, V., Jr. and Lane, N. (1957). Ann. Surg., 146, 117.

Binder, H. J., Herting, D. C., Hurst, V., Finch. S. C., and Spiro, H. M. (1965). New Engl. J. Med., 273, 1289.

Blanc, W. A., Reid, J. D., and Andersen, D. H. (1958). Pediatrics, 22, 494.

Blaschko, A. (1883). Virchows Arch. path. Anat., 94, 136.

Bogaert, L. van, and Tverdy, G. (1950). Mschr. Psychiat. Neurol., 120, 301.

Braunstein, H. (1961). Gastroenterology, 40, 224.

Casselman, W. G. B., Macrae, A. I., and Simmons, E. H. (1954). J. Path. Bact., 68, 67.

Cordes, D. O., and Mosher, A. H. (1966). Ibid., 92, 197.

Dinning, J. S. (1963). Nutr. Rev., 21, 289.

Fullerton, P. M. (1960). Brit. med. J., 1, 249.

Gresham, G. A., Cruickshank, J. G., and Valentine J. C. (1958) Nature (Lond.), 181, 538.

Herting, D. C. (1966). Amer. J. clin. Nutr., 19, 210.

Jarnum, S. (1963). Protein-losing Gastroenteropathy. p. 90. Blackwell, Oxford.

Kent, T. H., Layton, J. M., Clifton, J. A., and Schedl, H. P. (1963). Lab. Invest., 12, 1163.

Kerner, I., and Goldbloom, R. B. (1960). Amer. J. Dis. Child., 99, 597. Leonard, P. J., Losowsky, M. S., and Pulvertaft C. N. (1966). Gut, $7,578$. 
Lillie, R. D.: 1954). Histopathologic Technic and Practical Histochemistry, 2nd ed. Blakiston, New York.

—, Daft, F. S., and Sebrell, W. H. (1941). Publ. Hlth Rep. (Wash.), 56, 1255 .

Lindner, E. (1954). Arrtl. Forsch., 8, 1/505.

Majaj, A. S., Dinning, J. S., Azzam, S. A., and Darby, W. J. (1963). Amer. J. clin. Nutr., 12, 374

Mason, K. E., and Emmel, A. F. (1945). Anat. Rec., 92, 33. , and Telford, I. R. (1947). Arch. Path., 43, 363.

Nitowsky, H. M. Gordon, H. H., and Tildon, J. T. (1956). Amer. J. Dis. Child., 92, 491.

Pappenheimer, A. M., and Victor, J. 1946). Amer. J. Path., 22, 395.
Parkhurst, G. F., Grube, P. R., and Neumann, G. J. (1964). N.Y. St. J. Med., 64, 657.

Pearse, A. G. E. (1960). Histochemistry, Theoretical, and Applied, 2nd ed. Churchill, London.

Richards, W. C. D. (1959). Lancet, 1, 683.

Scheimpflug, M. (1885). Z. klin. Med., 9, 40.

Schwartz, M., and Jarnum, S. (1959). Lancet, 1, 327.

Tappel, A. L. (1965). Fed. Proc., 24, 73.

Toffler, A. H., Hukill, P. B., and Spiro, H. M. (1963). Ann. intern. Med., 58, 872.

Waldmann, T. A., Steinfeld, J. L., Dutcher, T. F., Davidson, J. D., and Gordon, R. S.. Jr. (1961). Gastroenterology, 41, 197. 